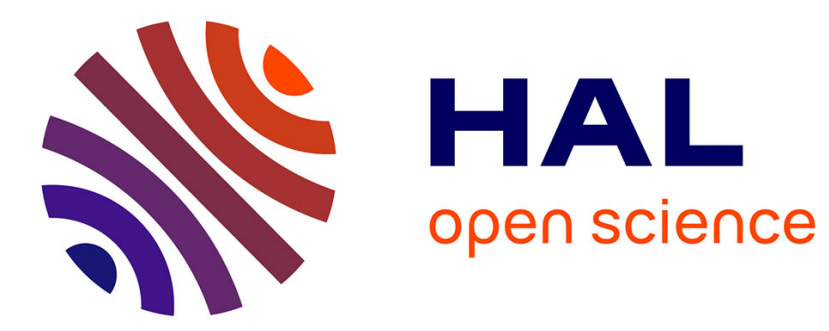

\title{
High magnetic field techniques for neutron and X-ray scattering
}

T.E. Wood

\section{To cite this version:}

T.E. Wood. High magnetic field techniques for neutron and X-ray scattering. Revue de Physique Appliquée, 1984, 19 (9), pp.685-690. 10.1051/rphysap:01984001909068500 . jpa-00245238

\section{HAL Id: jpa-00245238 https://hal.science/jpa-00245238}

Submitted on 1 Jan 1984

HAL is a multi-disciplinary open access archive for the deposit and dissemination of scientific research documents, whether they are published or not. The documents may come from teaching and research institutions in France or abroad, or from public or private research centers.
L'archive ouverte pluridisciplinaire HAL, est destinée au dépôt et à la diffusion de documents scientifiques de niveau recherche, publiés ou non, émanant des établissements d'enseignement et de recherche français ou étrangers, des laboratoires publics ou privés. 


\title{
High magnetic field techniques for neutron and $\mathrm{X}$-ray scattering
}

\author{
T. E. Wood \\ Oxford Instruments Ltd., Osney Mead, Oxford OX2 0DX, U.K.
}

\begin{abstract}
Résumé. - Depuis 1968, Oxford Instruments est à la pointe de la production d'aimants supraconducteurs pour champs magnétiques intenses ainsi que des systèmes cryogéniques pour les instituts de recherche du monde entier. On a assisté à une symbiose réussie entre les progrès technologiques, en particulier le développement de nouveaux matériaux, et les demandes de plus en plus précises des chercheurs. En ce qui concerne la construction des aimants supraconducteurs, leurs paramètres caractéristiques, comme le champ maximum, son homogénéité et l'accès à l'échantillon, sont discutés avec une attention particulière pour les expériences de diffusion des neutrons et rayons $\mathrm{X}$. Des exemples ont été choisis pour illustrer la grande variété des réalisations. Parmi ceux-ci, on peut citer les paires de bobines symétriques et asymétriques avec un grand accès angulaire couplées au système cryogénique. En fait, les possibilités de combinaisons du champ magnétique, de température et de configuration expérimentale sont aussi vastes que le permet l'imagination des chercheurs.
\end{abstract}

\begin{abstract}
Since 1968 Oxford Instruments has been at the forefront of the manufacture of not only reliable high field superconducting magnets but also low temperature systems for research institutes throughout the world. The succeeding years have been a period of fruitful symbiosis between technological progress, in particular the development of new materials, and the increasingly stringent demands of the researcher. The essential parameters of superconducting magnets such as the maximum field, its homogeneity and sample access will be described from a technical and constructional point of view with the emphasis on those aspects specific to the demands of neutron and X-ray scattering. Suitable examples will be provided to illustrate the wide variety of configurations that have been constructed. These include symmetric and asymmetric split pairs and wide angle horizontal access systems, most integrated with the means of cooling samples to low and ultra-low temperatures. In fact, the combinations of field, temperature and experimental configuration have ranged as wide as the imagination of the research worker.
\end{abstract}

\section{Introduction.}

The purpose of this talk is to describe and discuss some of the parameters which affect the design and construction of large superconducting magnets for research. By virtue of the special interests at this meeting my examples are confined to those that illustrate neutron and X-ray scattering investigations, though much of my material will, of course, be perfectly relevant to magnets used for other purposes.

Generally speaking, the degree of polarisation of a target is a function of $(H / T)$ so it is desirable to work at the highest fields and lowest temperatures. However, as the title of this talk implies, I shall restrict my subject matter to the magnetic field parameter as there are separate sessions devoted to the production of low and ultra low temperatures.

The construction of high field magnets has provided an excellent example of the benefits of multi-disciplinary approaches to the overall problem. In this case one can discern contributions from four (overlapping) scientific disciplines as follows :

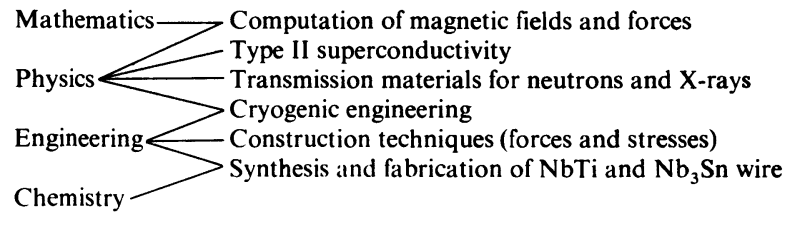

2. Magnetic design aspects.

2.1 Central field. - Magnets with design fields up to about 8 tesla are now based on the use of multifilamentary $\mathrm{NbTi}$ wire. This is an alloy of niobium and titanium containing $44-50 \%$ niobium which has a critical field at $4.2 \mathrm{~K}$ of about 10 tesla. The wire usually takes the form of multiple filaments of $\mathrm{NbTi}$, typically 61 for the magnets here discussed, embedded in a copper matrix. Inclusion of the copper significantly 
reduces the chance of a quench by reason of three (or more ?) mechanisms :

(i) The copper acts as an alternative current path allowing a local «normal " region to shed current to the copper, permitting the NbTi to cool and recover.

(ii) Rapid flux penetration is prevented by eddy current damping in the high conductivity copper.

(iii) The overall heat capacity is increased, hence a given flux jump causes a smaller temperature excursion.

It should be noted that for magnets with the split pair configuration the peak field on the windings is considerably higher than that at the magnet centre, restrincting the use of $\mathrm{NbTi}$ to central fields of less than 7 tesla.

Central fields of 10 tesla and above are obtained using the intermetallic compound $\mathrm{Nb}_{3} \mathrm{Sn}$ (critical field 18-23 tesla) [1]. Because $\mathrm{Nb}_{3} \mathrm{Sn}$ is brittle rather than ductile it must be synthesised after winding. The method used at present is to manufacture a ductile wire of niobium filaments embedded in a copper-tin bronze matrix. After winding this material is subjected to prolonged heat treatment at about $700{ }^{\circ} \mathrm{C}$ during which the tin diffuses through the bronze and reacts with the niobium to form the $\mathrm{Nb}_{3} \mathrm{Sn}$ superconductor.

In all cases, magnet performance is assisted by impregnating the windings with either epoxy resin or paraffin wax to mechanically stabilise the system.

2.2 Homogeneity. - This may conveniently be defined over a $10 \mathrm{~mm}$ diameter sphere at the magnet centre or over the whole sample volume if greater. It is frequently required that the nominal sample (and hence resonance) field does not overlap any nearby resonances. These vary, of course, with the type of measurement being performed, but typically range from $1 \%$ to $0.01 \%$.

The design procedure basically follows that described by Garrett [2] which provides a concise quantitative description of the field in a roughly spherical region using just a few coordinates. The required series summations may be conveniently performed using standard computer programs. It should be noted, however, that the expressions cannot be inverted and the procedure requires the selection of a « trial " set of coordinates, calculation of the appropriate field profiles and subsequent iteration. Fortunately, this process is tolerably efficient.

2.3 Persistence/DeCAY. - Research magnets of the type under discussion are usually designed so that the current leads may be disconnected after the magnet has been charged to full current. The degree of persistence then obtained is a function of the resistance between the joints. Joints are usually needed in all but the smallest coils, either to subdivide the coil into regions of different current density to match the local field, or simply because the available pieces of wire are not long enough.
With the jointing techniques developed over many years at Oxford Instruments, decay rates of 1 part in $10^{6}$ per hour may be readily achieved, whilst even more stringent requirements needed for NMR magnets ( 1 in $10^{9}$ or $10^{10}$ per hour) require that the magnet be designed so that the joints can be placed outside the regions of highest field.

\section{Magnet design. Physical aspects.}

3.1 Configuration. - The experimenter usually requires access in the horizontal plane for incident and scattered beams together with vertical access for the sample. This can be achieved with the split pair configuration shown in figures $1(a)$ and (b).
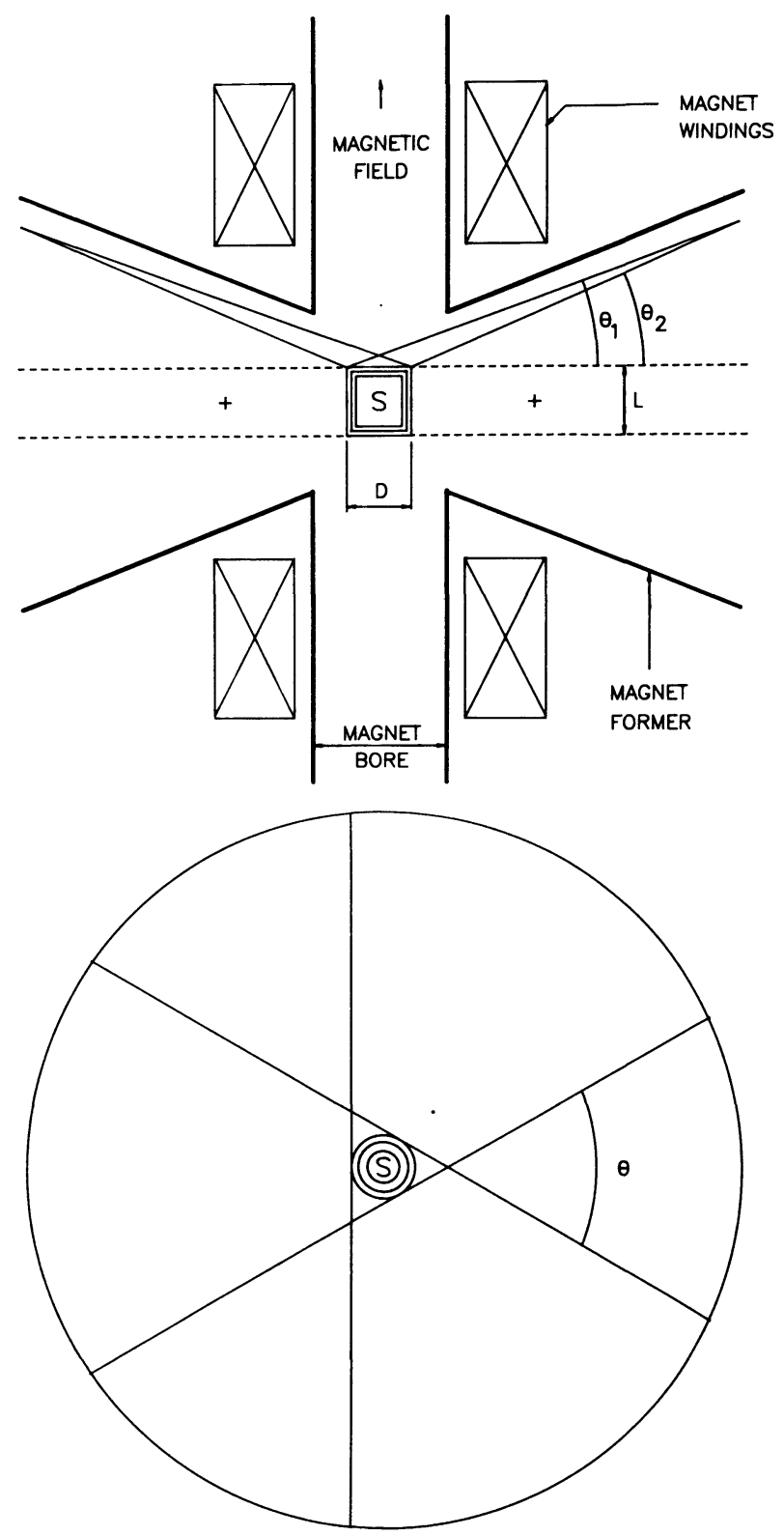

Fig. 1. - Schematic view of a split pair magnet showing beam and sample access. (a) Vertical section showing definition of angular access angles $\theta_{1}, \theta_{2}$ on sample $\mathrm{S}$ of length $L$ and diameter $D$. The crosses mark positions of null field. (b) Horizontal section through mid-plane of figure 1(a) showing « dark » angles $\theta$. 
All the given dimensions need to be precisely defined at an early stage. Sloping faces to the magnet formers are usually required (non zero $\theta_{1}, \theta_{2}$ ) as the cryostat and sample are not necessarily perpendicular to the beam.

The bore diameter will often be defined by the field homogeneity required. It must, of course, be sufficiently large to accommodate samples of useful size together with the means of cooling them with $\mathrm{He}^{4}, \mathrm{He}^{3}$ or a dilution refrigerator should this be required. In practice, there are geometrical requirements, arising directly from the mathematical expressions for the field profiles. This will mean that the ratio of bore diameter to split diameter will always be greater than 1 for a magnet of homogeneity $1 \%$ over $10 \mathrm{~mm}$ sample sphere, and will be greater still for systems of higher homogeneity.

3.2 FORCES. - Magnets of this type generate extremely large forces between coil sections. Although the use of aluminium alloy formers is desirable for homogeneity reasons the forces invariably necessitate using stainless steel.

The price paid is the risk of transformation of the steel to a ferromagnetic state through welding or cold forming. The support between the coils is shown in figure 1(b) as a set of wedges although continuous aluminium rings may also be suitable. Whilst wedges must be adequate to meet the mechanical requirements of the system it is often desirable from the experimental point of view to minimise the "dark " angles.

3.3 Windows. - Lastly, the cryostat must, of course, be able to transmit the probe beam : thin walled aluminium tail sections are usually used for neutron scattering experiments whilst beryllium and aluminised mylar windows meet the requirements of $\mathrm{X}$-ray systems. It is usually necessary to exclude liquid helium and nitrogen from the beam.

\section{Example systems}

4. 110 TESLA SYMMETRIC SPLIT PAIR WITH VERTICAL FIELD. - Figure 2 shows a vertical section through the magnet centre line of a 10 tesla system used for $\mathrm{X}$-ray scattering experiments along with the principal specifications. In this case the two halves of the magnet are supported by three sets of cryogenic feed tubes, one of which is shown in figure 2. This results in 3 " dark " angle wedges of $45^{\circ}$ in the horizontal plane. No access out of the horizontal plane was required in this case as the sample orientation could be changed within its cell using a special goniometer head. Dark angles can be avoided and Bragg angles matched by manual rotation of the sample with respect to the cryostat.

4.2 6 TESLA ASYMMETRIC SPLit PAiR. - This system has been designed for use with polarised neutron beams. Such a beam only remains polarised when it

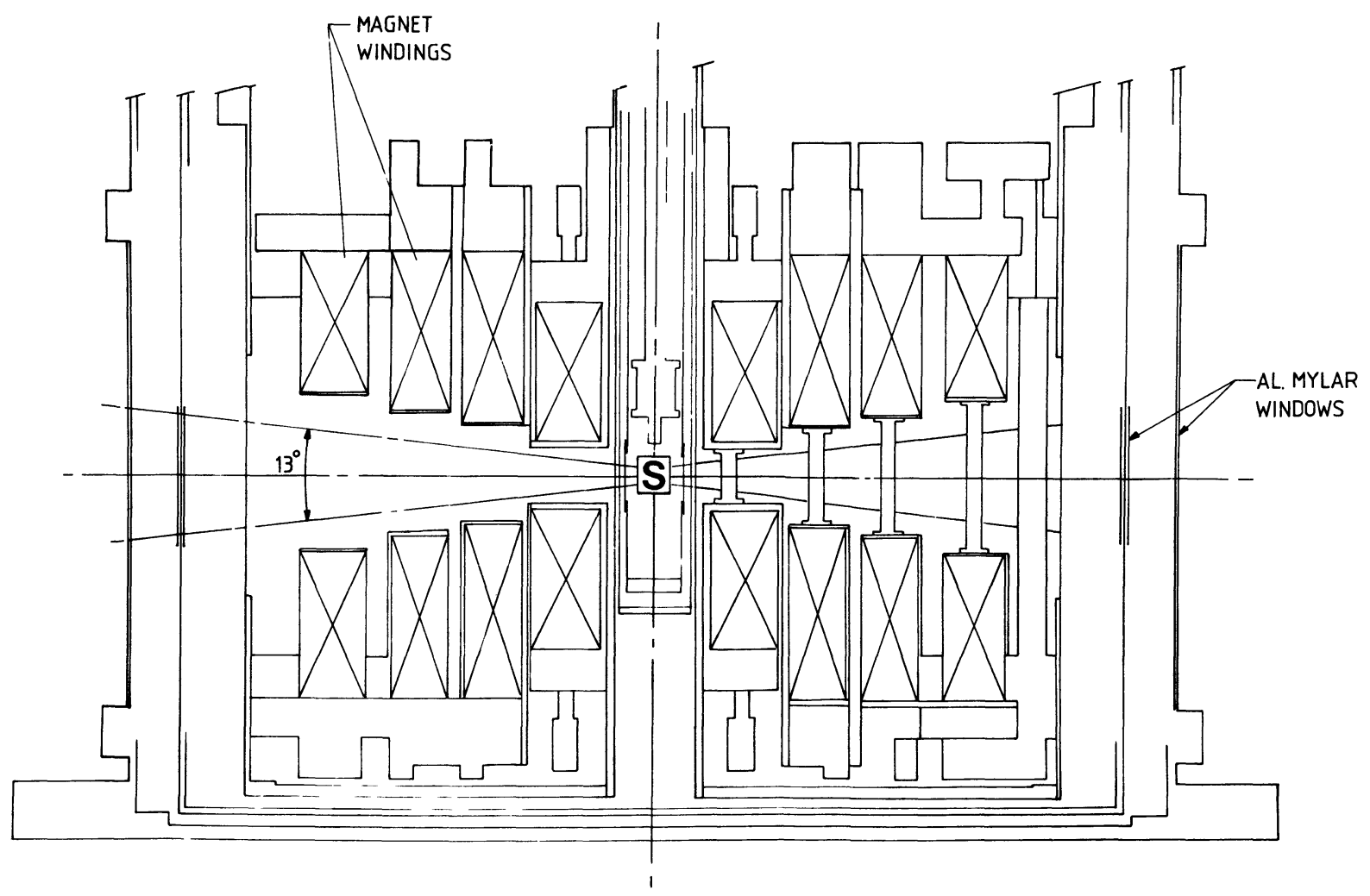

Fig. 2. - 10 tesla split pair for X-ray scattering. Central field : 10 tesla vertical. Homogeneity : $1 \%$ over $10 \mathrm{~mm}$ spherical volume. Clear bore : $31 \mathrm{~mm}$. Beam access : $\pm 6.5^{\circ}$ on to $5 \mathrm{~mm}$ vertical, $3 \times 75^{\circ}$ horizontal. No liquid helium or nitrogen in beam. Beryllium windows on sample cell and aluminised mylar windows on radiation shield. 
is travelling in a guide field of several millitesla and so the beam must not pass through any field nodes. The asymmetry of the windings is clearly visible in figure 3 .

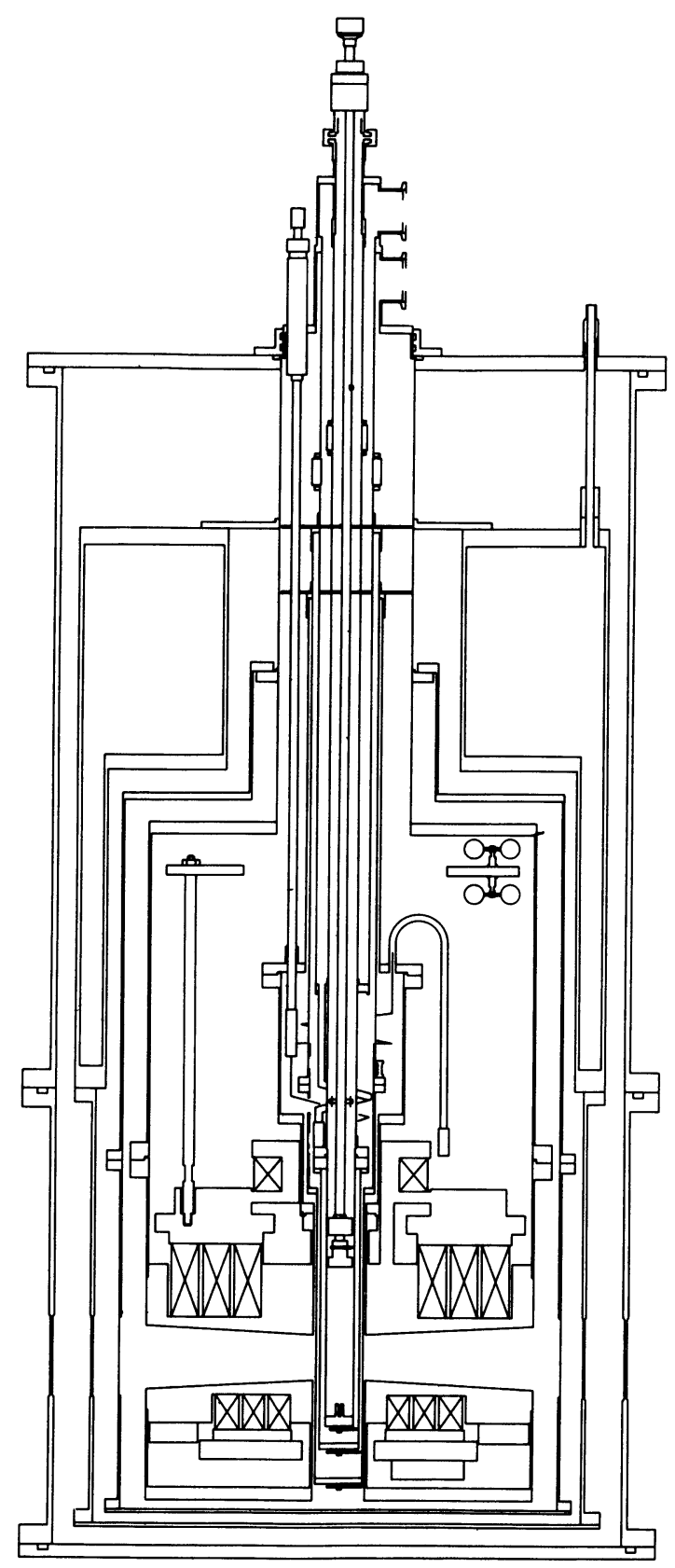

Fig. 3. -6 tesla asymmetric split pair for neutron scattering. Central field : 6 tesla vertical. Homogeneity : $4 \%$ over $40 \mathrm{~mm}$ $\times 25 \mathrm{~mm}$ diameter. Coil separation : $40 \mathrm{~mm}$. Magnet bore : $50 \mathrm{~mm}$. Beam access : $\pm 5^{\circ}$ vertical, $3 \times 10^{\circ}$ horizontal dark angles. Temperature range : 1.5-300 kelvin. Thermometry : field cancellation coil to provide low field region for $\mathrm{Rh}-\mathrm{Fe}$ sensor.

On a larger scale, figure 4 sketches the outline of windings for a symmetric (A) and asymmetric (B) split pair and shows how the field node (marked with a cross) may be removed from the beam path. It is necessary that the maximum rate of rotation of the field vector along the beam path be such that the neutron never precesses at its Larmor frequency in the field, or depolarisation will occur. The degree of asymmetry required depends directly on the fraction of the Larmor frequency that is acceptable.

Despite appearances, this arrangement need not be inconsistent with good homogeneity of the central field.

If each coil is placed on the Helmholtz line then there is no second order gradient, regardless of the strength of each coil. Balancing the axial (first order) gradient is obtained by taking advantage of the fact that this term is inversely proportional to the ampereturns of each coil and is equivalent to geometrical scaling [3]. This puts the weaker coil at the smaller radius, which can limit the homogeneity volume, whilst the coil on the larger radius will ultimately experience unacceptable hoop stresses.

4.34 TESLA SYSTEM WITH ROTATABLE FIELD VECTOR. This system was designed for particle scattering experiments and encompassed three important design parameters. Fistly, the magnet was constructed so that it could be mounted below the cryostat with the field vector either vertical (Fig. 5A) or horizontal (Fig. 5B).

In order to change the field orientation it is necessary to remove the tails of the cryostat, unbolt the magnet from a support ring and break three indium seals before assembling in the new orientation.

A second requirement was the elimination of liquid cryogen from the incident and scattered beams. For this reason the cryogenic services may be mounted in two positions on the magnet structure (see Fig. 5). Feed tubes are routed so that in either orientation cryogen enters at the bottom of the magnet.

Finally, and in order to facilitate a wide variety of experiments, angular access has been made extremely large : $90^{\circ}$ in the direction of the field vector and $\pm 7.5^{\circ}$ on to $62 \mathrm{~mm}$ perpendicular to the field.

\section{Future developments.}

Over the past 20 years we have seen a steady progress in the production of higher and higher magnetic fields, together with ever lower sample temperatures. This steady progress has, of course, been interrupted by jumps in performance such as the introduction of reliable $\mathrm{Nb}_{3} \mathrm{Sn}$ multi filamentary wire in the 1970's.

One current development concerns the 3 tesla system illustrated in figure 6 . This is a four coil split pair system for neutron scattering in which $335^{\circ}$ access is available in the horizontal plane which includes the field vector. The two halves of the magnet are supported by a $6 \mathrm{~mm}$ thick aluminium ring which is thin enough and of large enough diameter that it does not contribute significantly to scattering intensities. All electrical and cryogenic services are restricted to the $25^{\circ}$ dark angle. 


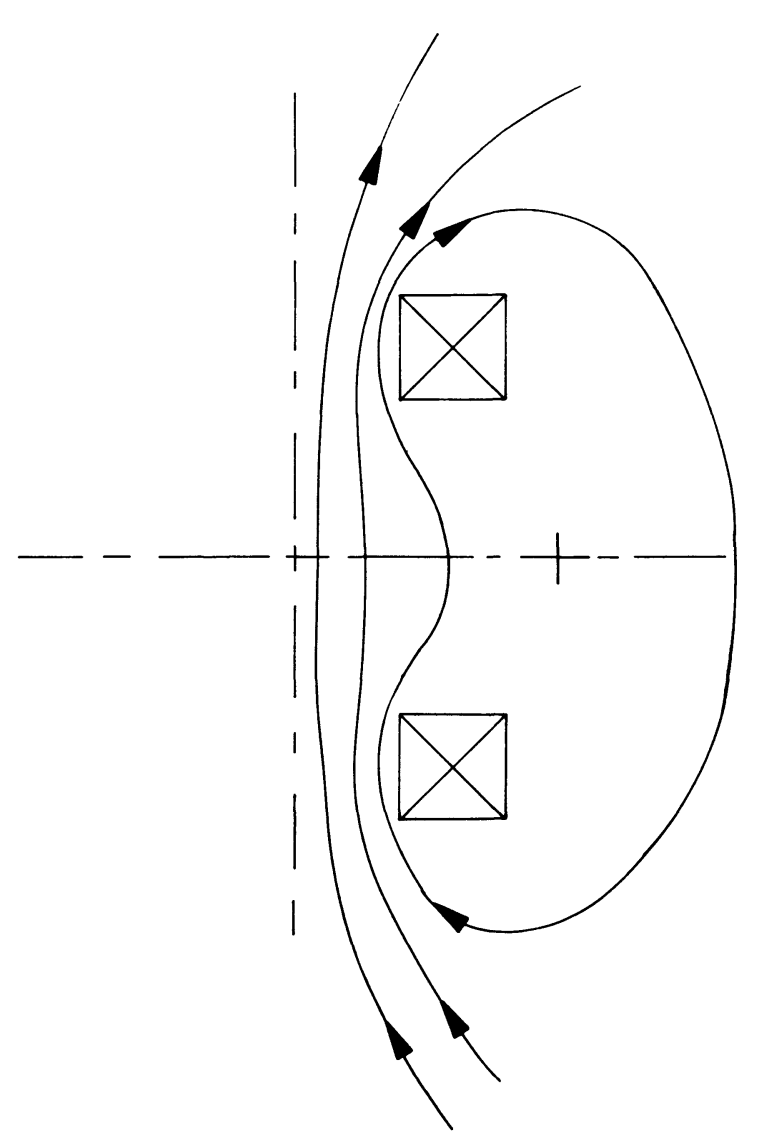

A

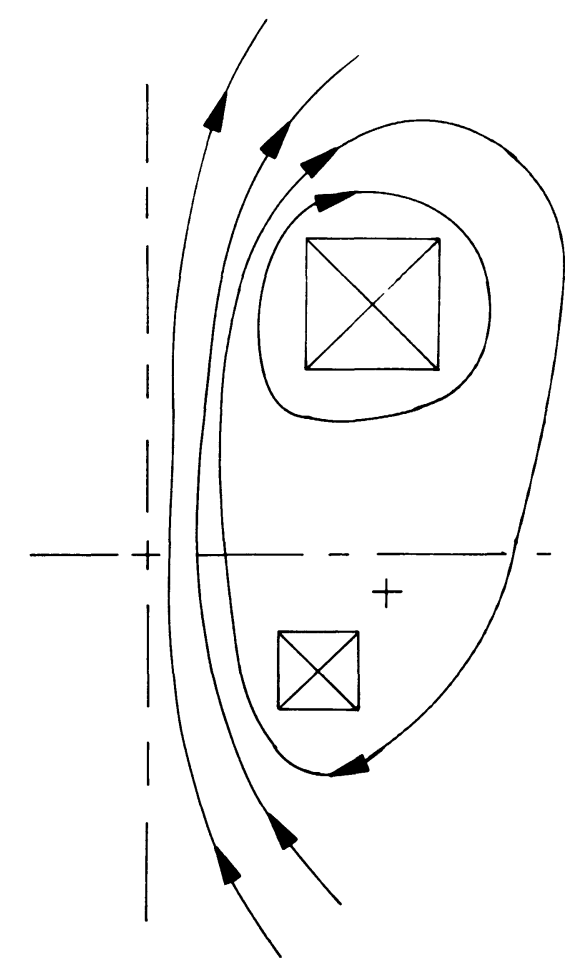

B

Fig. 4. - Symmetric (A) and asymmetric (B) split pair configurations. Crosses mark the field nodes $(B)=1$.

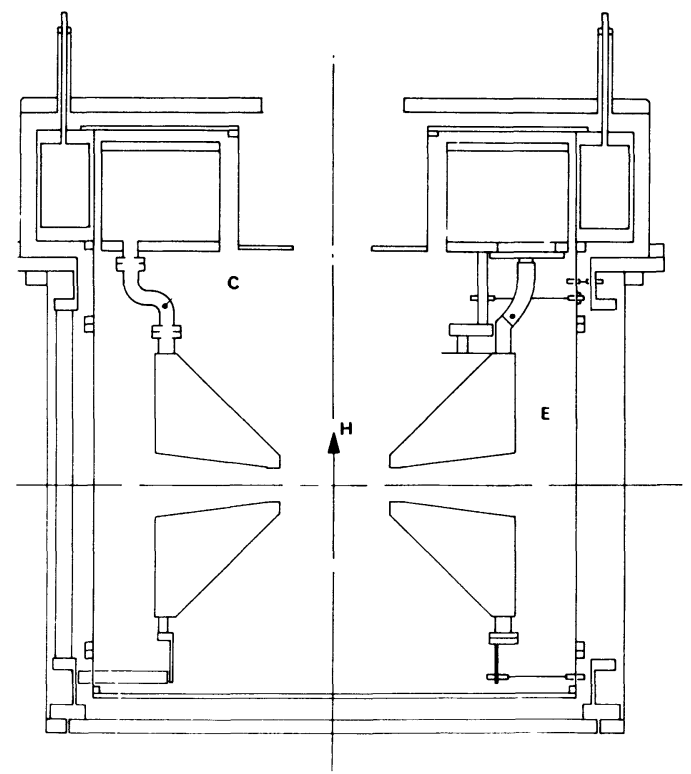

A

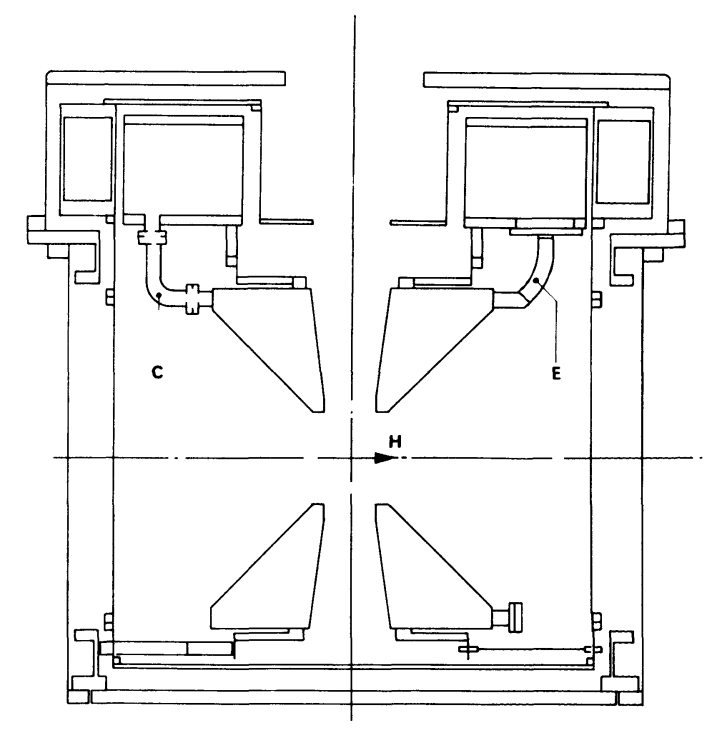

B

Fig. 5. - A large access vertical (A) and horizontal (B) system. C is the cryogenic service line, $\mathrm{E}$ the electrical services. Central field : 4 tesla vertical or horizontal. Homogeneity : $0.01 \%$ over $46 \mathrm{~mm}$ spherical volume. Clear bore : $160 \mathrm{~mm}$. Clear split : $62 \mathrm{~mm}$. Beam access (A) : $90^{\circ}$ vertical, $\pm 7.5^{\circ}$ on to $62 \mathrm{~mm}$ horizontal. No liquid cryogen in bore or split. 


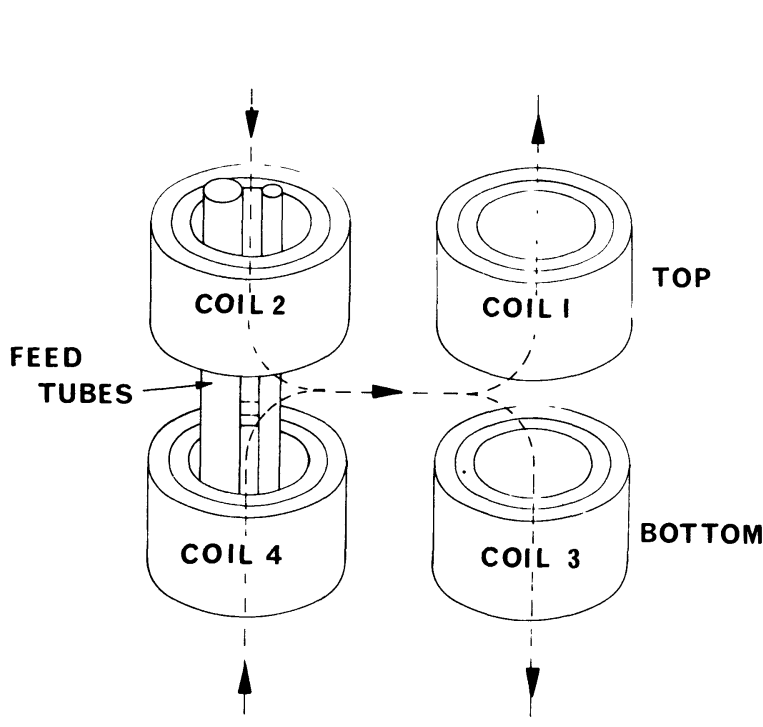

A

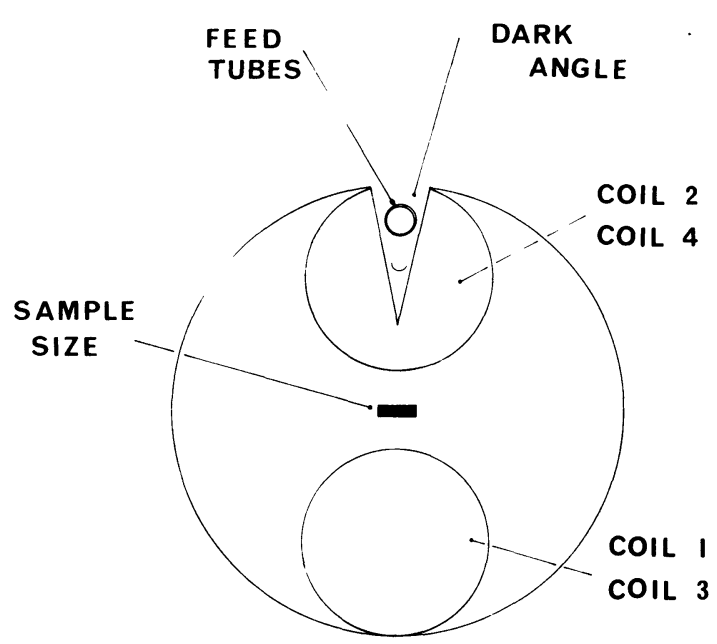

B

Fig. 6. - Coil configuration and plan view (in plane of field vector) of large horizontal access system. Guaranteed field : 3 tesla. Homogeneity : $10 \%$ over $38 \times 38 \mathrm{~mm}$ diameter cylinder. Operating current : $80 \mathrm{~A}$ approx. Clear bore : $60 \mathrm{~mm}$. Beam access : $335^{\circ}$ horizontal access on to $38 \mathrm{~mm}$.

Performance characteristics for superconducting wire continue to be enhanced. Much interest has been shown in the improvements achieved with $\mathrm{Nb}_{3} \mathrm{Sn}$ by doping with small quantities of other metals, such as titanium. Figure 7 compares the current densities versus field for pure and doped $\mathrm{Nb}_{3} \mathrm{Sn}$ [4] showing a factor of 2 enhancement at 16 tesla and significant usefulness beyond 20 tesla. At the moment, however, these technical possibilities are not fully realised on a commercial scale.

Fig. 7. - Critical current densities $\left(J_{\mathrm{c}}\right)$ versus field $(H)$ a 4.2 $\mathrm{K}$ for pure and Ti-doped $\mathrm{Nb}_{3} \mathrm{Sn}$ (Ref. [4]).

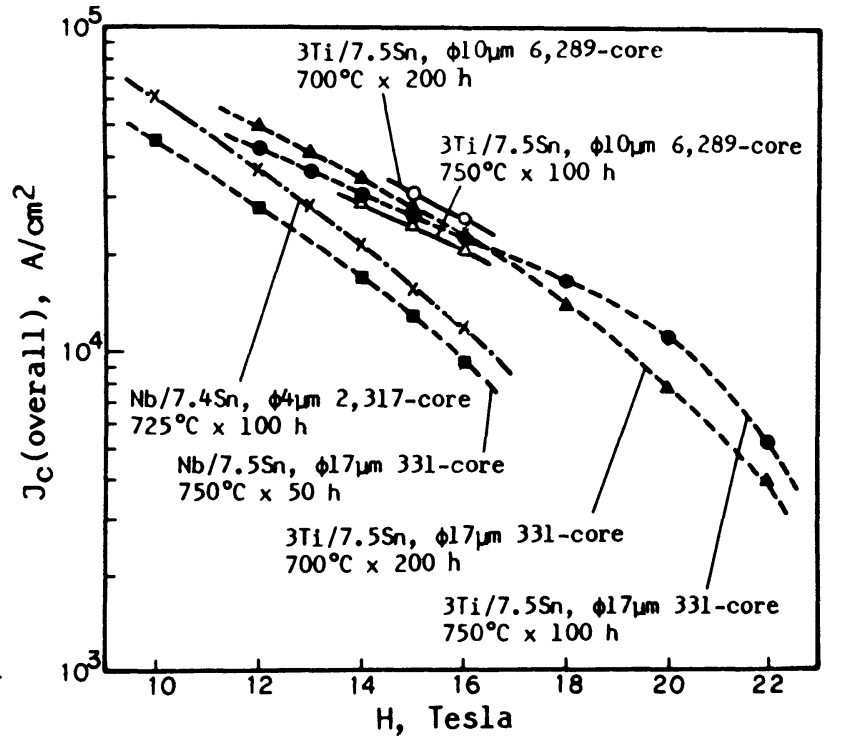

\section{References}

[1] McDonald, P. and Proctor, W., Proc. 8th Int. Cryogenic Eng. Conf. Genova 8 (1980) 509.

[2] Garrett, M. W., J. Appl. Phys. 22 (1951) 1091.

[3] Gilbert, E., Hanley, P., Hayter, J. B. and White, J. W., J. Phys. E 6 (1973) 714-718.

[4] Kamata, K., Tada, N., Itoh, K. and Tachikawa, K., IEEE Trans. Magn. MAG-19 (1983) 1433-6. 